\title{
INTERDISCIPLINARIDADE E FORMAÇÃO DE PROFESSORES
}

\author{
INTERDISCIPLINARITY AND TEACHER EDUCATION PROGRAM
}

\author{
Maria Madalena de Carvalho ${ }^{1}$
}

\begin{abstract}
RESUMO
Este ensaio é uma revisão bibliográfica acerca da interdisciplinaridade nos cursos de formação inicial de professores nas universidades brasileiras. $\mathrm{O}$ objetivo principal é identificar quais elementos caracterizam a prática docente interdisciplinar e os fatores que contribuem para essa prática. Levanta-se a teoria da interdisciplinaridade e a legislação-base da educação; identificam-se concepções, características, fundamentos epistemológicos, obstáculos e possibilidades da interdisciplinaridade. Também analisam-se estudos que discutem pontos essenciais da formação de professores e a perspectiva interdisciplinar. Nota-se a convergência de teóricos e pesquisadores ao reconhecerem a fragmentação do ensino nos cursos de licenciaturas e a necessidade do trabalho interdisciplinar mediante parceria entre escola e universidade para incentivar a pesquisa e o trabalho em equipes na formação interdisciplinar dos professores.
\end{abstract}

Palavras-chave: Interdisciplinaridade. Formação de professores. Licenciaturas.

\begin{abstract}
This paper is a literature review about interdisciplinarity on teacher education program in Brazilian universities. The aim of this essay is to identify which elements characterize the interdisciplinary teaching practices and the factors that contribute to this. Raises the theory of interdisciplinarity and education legislation base, the essay identifies concepts, features, epistemological foundations, obstacles and possibilities of interdisciplinarity. Also, it analyzes studies that discuss key issues of teacher education program and interdisciplinary perspectives. Note the convergence theorists and researchers to recognize the fragmentation of education in undergraduate courses and the need for interdisciplinary work through a partnership between schools and universities to encourage research and work teams in the interdisciplinary teacher education program.
\end{abstract}

Key-words: Interdisciplinarity. Teacher education program. Teacher education degrees.

\section{Introdução}

Transformações sociais decorrentes da globalização econômica, social e cultural, mediadas pela rápida evolução das tecnologias da informação marcam a atualidade, provocando mudanças em todos os setores sociais. A importância do conhecimento é destacada em todos os segmentos da sociedade contemporânea. E o papel social da escola é colocado em questão pela comunidade escolar, pesquisadores e teóricos da educação, por não conseguir acompanhar o ritmo do desenvolvimento das coletividades. A

\footnotetext{
${ }^{1}$ Programa de Pós-Graduação Mestrado em Educação. Universidade Federal do Triângulo Mineiro - UFTM. E-mail: magdalabrasil@gmail.com
} 
complexidade, característica dos problemas hodiernos, desafia a inteligência a repensar os modelos de educação vigentes, promovendo discussões e estudos sobre possíveis reformas.

Nesse panorama, a UNESCO (BRASIL, 2003) apresentou um estudo das perspectivas da educação para o século XXI. Apontou quatro pilares básicos necessários à formação integral: i) aprender a conhecer: habilidade de integrar conhecimentos para compreender a realidade e seus problemas; ii) aprender a fazer: saber relacionar e construir conhecimentos e suas aplicações no contexto social; iii) aprender a conviver: aptidão para viver em comunidade e trabalhar em equipe, aceitar o outro e as diferenças; iv) aprender a ser: respeitar e cultivar as diversas dimensões humanas, enquanto corpo, espírito, inteligência e afetividade. Destarte, a proposta sugeriu uma prática pedagógica ancorada nessas aprendizagens fundamentais, aptas a fornecerem mapas e a bússola para navegar num mundo complexo e instável.

Nessa abordagem, a aprendizagem contempla múltiplas dimensões que Masetto (1997, p. 14) explicitou: “[...] o desenvolvimento da pessoa como um todo: inteligência; afetividade; padrões de comportamento moral; relacionamento com a família, com o bairro, com a cidade e com o país; desenvolvimento da coordenação motora; capacidades artísticas; comunicação.", focando a aprendizagem nos aspectos humano, sociopolítico e técnico. Todas as perspectivas indicadas exigem o aprimoramento da ação docente para além do domínio dos conteúdos específicos.

Edgar Morin (2007, p. 10-11) aprofundou a questão ao tratar da significativa diferença entre educação, formação e ensino. Para ele, formação tem sentido de moldagem e conformação, com o agravante de desconsiderar que a didática precisa estimular o autodidatismo, propiciando o desenvolvimento da autonomia; ensino "[...] é arte ou ação de transmitir conhecimentos a um aluno, de modo que ele compreenda e assimile, tem sentido mais restrito, porque apenas cognitivo.” E educação, segundo ele, é um conceito mais amplo, capaz de nos ajudar a sermos melhores e vivermos mais felizes. Para Morin (2007), todo ensino precisa ser educativo, porque "[...] a missão do ensino é transmitir, não o mero ensino, mas uma cultura que permita compreender a nossa condição e nos ajude a viver, e que favoreça, ao mesmo tempo, um modo de pensar aberto e livre". Nesse horizonte, a proposta de educação para a contemporaneidade sugere um novo perfil de professor, aberto à mudanças, à inovação e ao trabalho em equipe.

No mundo contemporâneo, o conhecimento deve ser significativo e apresentar-se disposto a enfrentar a complexidade. O saber “ [...] torna-se pertinente quando é capaz de 
situar toda informação em seus contextos e, se possível, no conjunto global no qual se insere [...]" (MORIN, 2007, p. 15). Para esse pesquisador (2003), o complexus é aquilo que foi tecido junto, composto de diferentes elementos que não são separáveis do todo, determinados pela interdependência e a inter-retroatividade entre o todo e as partes entre si, o objeto de análise e contexto. A conjuntura dos problemas atuais abrange múltiplos aspectos: econômico, cultural, ecológico, político, sociológico, psicológico, afetivo, mitológico dentre outros. Nessa composição, a sociedade e o ser humano são unidades complexas e comportam muitas dimensões.

Entretanto, vigora no ensino contemporâneo, inclusive na universidade, a cultura do conhecimento fragmentado, dividido e sitiado em conteúdos disciplinares. Essa prática em sala de aula não possibilita aos alunos integralizar saberes para análise dos problemas da realidade, nem captar a totalidade e a multidimensionalidade que envolve o indivíduo e a sociedade. Morin (2003), observando separação das disciplinas nas escolas, escreve:

A supremacia do conhecimento fragmentado de acordo com as disciplinas impede frequentemente de operar o vínculo entre as partes e a totalidade, e deve ser substituída por um modo de conhecimento capaz de aprender os objetos em seu contexto, sua complexidade e seu conjunto. (MORIN, 2003, p. 14).

Essas reflexões somadas a estudos de outros pesquisadores como George Gusdorf, Piaget, Ivani Fazenda e Hilton Japiassu apresentaram a interdisciplinaridade como metodologia para superar a fragmentação do conhecimento e resgatar o aspecto da totalidade que encerra os mais amplos aspectos da vida e do indivíduo pela humanização do conhecimento, tanto na ciência como no ensino. Gusdorf (1975, p. 24), enfatizou que a falta da interdisciplinaridade expressa "a perda do sentido humano, o desaparecimento de toda imagem reguladora que preservaria a figura do homem num mundo à sua escala".

Piaget (2007) definiu a interdisciplinaridade como forma de pensar, ampliando a conceituação do termo para além da metodologia e organização curricular, evidenciando-a como habilidade cognitiva associada ao "aprender a aprender". Expressada no exercício do raciocínio ao apropriar-se dos conhecimentos diferentes e articulá-los para analisar o mundo.

Fazenda (2011, p.11) também conceituou a interdisciplinaridade na educação e esclareceu a diferença entre integração, interação e interdisciplinaridade. Para a autora, interdisciplinaridade é uma questão de “[...] atitude de abertura, não preconceituosa, em que todo conhecimento é igualmente importante [...]". Afirmou que "[...] a metodologia é indiscutível, porém é necessário não fazer dela um fim, pois interdisciplinaridade não se 
ensina e nem se aprende, apenas vive-se, exerce-se e, por isso, exige uma nova pedagogia, a da comunicação.” Nesse sentido, diferenciou as fases integração e interação:

\begin{abstract}
A integração refere-se a um aspecto formal da interdisciplinaridade, ou seja, à questão de organização das disciplinas num programa de estudos. [...] Entretanto, essa integração não pode ser apenas no nível da integração de conteúdos ou métodos, mas basicamente no nível de integração de conhecimentos parciais, específicos, tendo em vista um conhecer global. Interação: É condição de efetivação da interdisciplinaridade. Pressupõe uma integração de conhecimentos visando novos questionamentos, novas buscas, enfim a transformação da própria realidade. (FAZENDA, 2011, p. 11-12)
\end{abstract}

Assim, mais que integração curricular é preciso interação; mais que interação é preciso atitude para que a interdisciplinaridade aconteça na sala de aula. Segundo a autora, a interdisciplinaridade caracteriza-se pela reciprocidade nas trocas de conhecimento e experiências, objetivando melhoria mútua. Ampliando a compreensão da atitude interdisciplinar, Japiassu (1976) afirmou que trabalho interdisciplinar requer a seguinte postura do professor ou do pesquisador:

[...] o verdadeiro espírito interdisciplinar consiste nessa atitude de vigilância epistemológica capaz de levar cada especialista a abrir-se às outras especialidades diferentes da sua, a estar atento a tudo o que nas outras disciplinas possa trazer um enriquecimento ao seu domínio de investigação e a tudo o que, em sua especialidade, poderá desembocar em novos problemas e, por conseguinte, em outras disciplinas. $\mathrm{O}$ espírito interdisciplinar não exige que sejamos competentes em vários campos do saber, mas que nos interessemos, de fato, pelo que fazem nossos vizinhos em outras disciplinas. (JAPIASSU, 1976, p.138)

Interdisciplinaridade, nessa perspectiva, acontece numa relação dialógica, em que o professor numa atitude de pesquisa toma conceitos e instrumentos de outras disciplinas para aprimorar o processo de ensino, facilitando a aprendizagem e ampliando as possibilidades de interpretação e visão do fenômeno ou "conteúdo" para os alunos.

Diante desse cenário, o objetivo do ensaio é refletir sobre a interdisciplinaridade na formação de professores. No intento, encetamos uma revisão bibliográfica, objetivando verificar a efetivação da interdisciplinaridade nos cursos de formação inicial das universidades brasileiras. Também buscamos identificar nas pesquisas sobre formação de professores quais elementos caracterizam uma prática docente interdisciplinar e os fatores que contribuem para práticas interdisciplinares. 


\section{Interdisciplinaridade - normatização e institucionalização}

As instituições de ensino superior expressam em sua política organizacional, acadêmica e científica, o intento de propiciar uma formação interdisciplinar. Nos cursos de licenciatura há direcionamentos claros, recomendando adequação dos currículos e das práticas de ensino à metodologia interdisciplinar. É possível observar no âmbito de uma universidade federal, por exemplo, orientações apontando para dimensões teóricas e práticas da interdisciplinaridade no Projetos Pedagógico Institucional (PPI) e no Projeto Pedagógico dos Cursos (PPC).

Com a Constituição Federal de 1988 (BRASIL, 1988), as universidades conquistaram autonomia didático-científica. Esse avanço possibilitou construir a identidade de cada instituição, por meio da organização de seus projetos pedagógicos, construídos de forma participativa e contextualizada. A Carta Magna propôs uma educação mais abrangente, envolvendo os processos formativos na vida familiar, no trabalho, nas instituições de ensino e pesquisa, na sociedade e nos movimentos culturais. Acrescentou, ainda, que a educação escolar precisa relacionar-se com o mundo do trabalho e à prática social.

Nota-se, também, que a Lei n. 9.394/96, de Diretrizes e Bases da Educação Nacional - LDBN (BRASIL, 1996) e a Constituição Federal (BRASIL, 1988) reservaram ao ensino superior objetivos de incentivar a criação cultural e desenvolver o pensamento reflexivo, o espírito científico tendo em vista atender necessidades sociais. Essa é a missão da universidade junto à sociedade e o sentido da educação. Respeitar a liberdade de criar, de perquirir, de refletir para formar cidadãos aptos à colaborar e transformar a vida social. Nesse entendimento, a relação entre indivíduo e conhecimento é conduzida por interações dinâmicas com a realidade vivida. Portanto, significativa e contextualizada, apta a preparar sujeitos livres e profissionais com habilidades intelectuais para interpretar a complexidade da vida contemporânea.

Outro documento importante foi a Resolução n. 1, de 2002 (BRASIL, 2002) que organizou as Diretrizes Curriculares Nacionais para a Formação de Professores da Educação Básica, em nível superior, dos cursos de licenciatura. Instituiu princípios, fundamentos e procedimentos para a organização institucional e curricular. Firmou a flexibilidade do currículo, conferindo a responsabilidade de sua organização às instituições de ensino. Sinalizou, também, para dimensões teóricas e práticas de interdisciplinaridade, 
no artigo 13: "Em tempo e espaço curricular específico, a coordenação da dimensão prática transcenderá o estágio e terá como finalidade promover a articulação das diferentes práticas, numa perspectiva interdisciplinar”. Desde então, os Projetos Pedagógicos Institucionais e os Projetos Pedagógicos dos Cursos previram ações, políticas e práticas interdisciplinares.

Entretanto, em cursos de licenciaturas nas universidades federais, embora as normatizações e regulamentações disponham sobre a interdisciplinaridade nesses cursos de formação de professores, a realidade é bem outra. Na prática isso não acontece. Feldeman (2014) analisando a preparação de professores no contexto institucional anotou que nessa formalização interpenetram conhecimentos e ações para ensejar um espaço institucional de possibilidades para formação interdisciplinar. Todavia, aduziu a autora, essas possibilidades se amparam em duas dimensões: a dimensão do documento e a dimensão do movimento. Na dimensão do documento constam as intenções de uma formação interdisciplinar registrada em normatizações, relatórios, projetos, mas não há movimento no sentido de concretizar tais postulados. Essas iniciativas não passam do papel, pois, é na dimensão do movimento que se articulam concepções e condições necessárias para a vivência do proposto.

Em nosso país, asseverou Fazenda (2011, p. 20), mesmo com as políticas públicas apontando diretrizes e ressaltando a necessidade da interdisciplinaridade, essa continua ignorada na experiência e difícil de ser implantada devido ao "[...] rito das cabeças deformadas pelo acúmulo de conteúdos [...]”, que ainda impera. Porém, é oportuno ressaltar a importância dos primeiros passos com o reconhecimento expresso da necessidade de mudanças e vivência da interdisciplinaridade no contexto universitário. É evidente que ainda faltam políticas e ações incentivadoras de práticas interdisciplinares nos cursos de formação inicial de professores. Mas, o caminho está aberto.

\section{Interdisciplinaridade - perspectivas na formação de professores}

A formação de professores com habilidades para atuar de forma interdisciplinar foi considerada por Piaget como condição de avanço para uma pedagogia que transcenda as barreiras da excessiva especialização, estabelecida pela cultura científica e acatada na educação. Segundo esse pesquisador, o ensino precisa de uma "[...] redução geral das barreiras ou para a abertura de múltiplas portas laterais a fim de possibilitar aos alunos 
(tanto de nível secundário, quanto de nível universitário) a livre transferência de uma seção para outra, com possibilidade de escolha de múltiplas combinações." (PIAGET, 2007, p.23). Ele afirma que o maior obstáculo à interdisciplinaridade será obter dos professores essa descentralização dos saberes.

Fazenda (2003) identificou em sua pesquisa os principais obstáculos à efetivação da interdisciplinaridade, destacando como mais difícil a formação de professores, porque será preciso mudar de uma relação pedagógica fundamentada na transmissão de conhecimento de uma determinada disciplina para uma relação dialógica em que são considerados igualmente importantes todos os saberes, o que requer interação e parcerias entre professores.

Nessa perspectiva, a interdisciplinaridade na formação de professores foi analisada por Neves (2015) como fator indispensável à qualidade, por atender às características da vida contemporânea:

\begin{abstract}
A interdisciplinaridade tem complexidade própria que combina os desafios de ordem curricular, metodológica, tecnológica e pedagógica da educação. Sua aceitação, porém, amplia perspectivas, abre novas linhas de pesquisa, une contextos plurais, promove sínteses capazes de aproximar áreas e setores que se julgavam alheios ao objeto de estudo, gera avanços cognitivos qualitativos, induz à adoção de novas modalidades de produção e compartilhamento de conhecimento. Essas características fazem da interdisciplinaridade uma necessidade epistemológica e uma exigência prática do mundo contemporâneo, o que a torna uma aliada na busca da excelência da formação de professores. (NEVES, 2015, p.497)
\end{abstract}

Compartilhar conhecimentos e trabalhar em equipes são fatores que mais dificultam a adesão dos professores, pois estão acostumados com a cultura tradicional de ensino, baseada na transmissão e memorização de conteúdos, centralizada no professor. Um caminho possível para a interdisciplinaridade está nos cursos de preparação dos docentes. Consultando pesquisas de vários teóricos, colhemos pontuações que conduzem a refletir sobre formação de professores numa perspectiva interdisciplinar.

Garcia (1999) afirmou que na sociedade que elegeu o conhecimento como principal predicativo, a formação de professores torna-se necessidade relevante, porque muito além de técnicas e conteúdos é necessário ter em vista o desenvolvimento de um perfil docente com postura convicta, responsabilidade, determinação para enfrentamentos e abertura para 
mudanças. Enfatizou que o conceito de formação docente não é uniforme. Em razão disso, destacou a concepção que ultrapassa a formação profissionalizante, restrita ao exercício meramente reprodutivo dos conteúdos e compartilhou com Medina e Domínguez ao definirem a formação docente como:

“[...] a preparação e a emancipação do profissional docente para realizar crítica, reflexiva e eficazmente um estilo de ensino que promova uma aprendizagem significativa nos alunos e consiga um pensamento acção inovador, trabalhando em equipa com os colegas para desenvolver um projecto educativo comum". (MEDINA E DOMÍNGUEZ, 1989apud GARCIA, 1999, p. 23)

Essa concepção sublinhou aspectos importantes para a educação do terceiro milênio. Toma por base desenvolver a criticidade e reflexividade, ensejando o desenvolvimento do hábito de analisar, pensar e repensar as práticas e os contextos buscando inovar; criar um "estilo de ensino" próprio, ao priorizar a autonomia e a originalidade peculiares da prática educativa. Revelou o cuidado de evitar a massificação do fazer docente, quando utiliza técnicas e receitas prontas. Promoveu a educação significativa ao enlaçar conteúdos e teorias à prática e ao contexto social dos aprendentes. E, por fim, salientou o trabalho em equipe, em projetos comuns originados de problemas reais, desenvolvidos em parcerias. Essas características remetem à prática da interdisciplinaridade.

O fazer docente transcende os limites da profissão e consolida-se como prática social; é uma “[...] forma de intervenção no mundo [...]” (FREIRE, 1996, p. 98), razão pela qual a autonomia apresenta-se como condição natural para educar, refletindo peculiaridade e estilo próprios do professor, decorrentes da cultura, da escola, a realidade e os alunos considerados em suas individualidades. Buscando elucidar o conceito formação docente e sua relação com a prática, lembramos Mattos (1999, p. 8), que apontou:

[...] valorização da experiência vivida como processo intersubjectivo, cujos ingredientes, materiais e simbólicos, revelando, embora, dos contextos socioinstitucionais que constituem a matéria-prima da formação, representam as condições de possibilidade para sua própria transformação, quando reflectidos como objectivados nos próprios contextos socioinstitucionais e práticas de trabalho de que são, simultaneamente, condição e emanação. (MATTOS, 1999, p.8)

Esse é o sentido da formação do professor, a experiência vivida, interna e externamente, nos contexto da instituição de ensino e da sociedade. Essa prática cria e 
recria continuamente condições aperfeiçoadoras do saber docente, vez que as situações da sala de aula propiciam aprendizagem e motivações para a pesquisa e estabelecem, naturalmente, a contínua formação.

Segundo Pimenta (2012, p. 17), “[...] professorar não é uma atividade burocrática para a qual se adquire conhecimentos e habilidades técnico-mecânicas [...]". Nessa perspectiva, explicitou que na formação continuada, com frequência, a prática é oferecer cursos de suplência e/ou atualização dos conteúdos de ensino. E, no mesmo sentido, os cursos de formação inicial permanecem nas teorias da reprodução, restringindo a ilustrar professores sem propiciar articulação e transformação dos novos saberes em novas práticas. Amparada em dados de pesquisas, a autora afirmou que cursos de formação desenvolvem currículos formais com conteúdos e estágio dissociados da realidade da escola, num panorama burocrático e cartorial, que não capta as contradições presentes na prática social de educar; portanto, não colaboram para a gestação de uma nova identidade profissional docente. Vejamos:

\footnotetext{
Dada a natureza do trabalho docente, que é ensinar como contribuição ao processo de humanização dos alunos historicamente situados, espera-se da licenciatura que desenvolva nos alunos conhecimentos e habilidades, atitudes e valores que lhes possibilitem permanentemente irem construindo seus saberesfazeres docentes a partir das necessidades e desafios que o ensino como prática social lhes coloca no cotidiano. Espera-se, pois, que mobilize os conhecimentos da teoria da educação e da didática necessários à compreensão do ensino como realidade social, e que desenvolva neles a capacidade de investigar a própria atividade para, a partir dela, constituírem e transformarem o seus saberes-fazeres docentes, num processo contínuo de construção de suas identidades como professores. (PIMENTA, p. 18, 2012)
}

A autora comentou, ainda, acerca da formação inicial e continuada dos professores desvinculada das escolas e a fragmentação dos saberes da docência (saberes da experiência, saberes científicos e saberes pedagógicos) nas licenciaturas. Concluiu ela pela necessidade de superação, pela renovação dos métodos e sistemáticas de organização das escolas, envolvendo organização curricular, interdisciplinaridade, currículos e estágios articulados com as escolas-campo.

Pesquisa realizada por Saviani (2009) também apontou esse desequilíbrio na organização curricular da formação inicial dos professores nas universidades. Constatou a maior valorização da aprendizagem dos conteúdos específicos em detrimento da preparação pedagógica. Esse fato contribui para que a prática docente priorize o repasse de 
conteúdos, diminuindo o foco das questões de ensino e aprendizagem. Essa dissociação entre os saberes didático-pedagógicos e conteúdos específicos, nos cursos de formação inicial de professores, reflete nas práticas docentes na escola e na sala de aula, evidenciando o despreparo quanto ao domínio do conhecimento de como ensinar.

Para ilustrar a situação, a pesquisa de Gatti e Sá Barreto (2009) constatou que em nosso país, os currículos dos cursos de Pedagogia apresentam desequilíbrio ao contemplar $30 \%$ de disciplinas para formação específica, relativa ao o que e como ensinar e habilidades específicas da docência; e 70\% para disciplinas de conteúdos diversos. Essas porcentagens revelaram a fragmentação e a pouca relação entre teoria e prática nos referidos cursos.

Nessa vertente, entendemos que a formação inicial do professor precisa de um currículo vivo, articulado à realidade e aos problemas atuais, de maneira a propiciar formação de professores aptos a promoverem transformações sociais pela educação, conscientes de seus papeis na escola e na sociedade, conhecedores dos conteúdos a ponto de integrá-los interdisciplinarmente. Com sua atividade, que os professores possam ensinar ao aluno não só construir conhecimentos, mas inter-relacioná-los para compreender e atuar na realidade social cheia de incertezas, no mundo globalizado, em sucessivas transformações.

Nesse contexto, Shulman (2005) defendeu uma reforma do ensino que destaque a compreensão e o raciocínio, a transformação e a reflexão. Refletiu sobre os conhecimentos básicos necessários aos professores e as políticas de formação inicial dos professores, ressaltando que a duração dos cursos de formação inicial é muito pequena para comportar todo o conhecimento necessário aos professores em suas lidas na sala de aula. Enumerou as categorias básicas necessárias ao docente elencando: conhecimento didático geral; conhecimento de currículo; conhecimento didático de conteúdo; conhecimento dos alunos e suas características; conhecimento do contexto escolar, da realidade do entorno, da cultura da comunidade e conhecimento dos objetivos e finalidades da educação, valores educativos e fundamentos filosóficos históricos.

Dentre essas categorias, o autor sublinhou o conhecimento didático. Segundo ele, esse conhecimento permite identificar e distinguir conteúdos, mesclar a matéria à didática para compreender a composição, a organização dos temas e problemas, bem como adaptálos para diversos interesses e capacidades dos alunos, explorando as várias possibilidades para o trabalho do professor, do pedagogo e especialistas na área de educação. 
Nas considerações de García (1999), outro aspecto importante a ser estimado é a organização curricular na formação de professores, porque sempre repercutiram aspectos políticos, econômicos e sociais, pois, ao escolher o que e o como estudar para formar um docente há uma subjetividade expressa no sentido de modelo de escola, de ensino e de professor pretendidos. $\mathrm{Na}$ sociedade capitalista, em que a educação tende a servir para formar profissionais e mão de obra qualificada, a tendência é o ensino técnico, objetivando mais a qualificação profissional. Assim, na formação inicial docente, é clara a organização curricular enfatizando os conteúdos disciplinares em detrimento da formação integral do licenciando.

Desse modo, é comum o currículo segmentado como modelo habitual nos cursos de licenciaturas, inviabilizando ao futuro professor o desenvolvimento de uma visão sistêmica, na qual o conhecimento se relaciona com as necessidades sociais. Essa cultura ecoa na educação básica, uma vez que docentes formados para transferir conteúdos específicos, como Matemática, Português, Geografia e História, por exemplo, não sabem integrar tais conteúdos com o mundo real. Essa falta de contextualização na prática de ensino não atribui significado aos conteúdos disciplinares e repercute no pouco interesse dos alunos nos estudos, por não fazerem sentido no cotidiano.

Nesse sentido, Silva (2000) apresentou interessante análise sobre os cursos de formação de professores, destacando o aspecto da reflexão crítica sobre as próprias práticas, muito enfatizada quando se fala em formação docente. Apontou que nas práticas de formação continuada é mais valorizada a racionalidade técnico-instrumental, direcionando para a exterioridade em prejuízo da análise crítica e reflexiva dos formandos. Destarte, sustentou que a formação de professores precisa contemplar não somente o desenvolvimento de conhecimentos, mas também o desenvolvimento de competências em três dimensões: i) competências profissionais que compreendam o conhecimento científico e o domínio de conteúdo; ii) competências pedagógicas que abarquem o saber operacionalizar, saber fazer, considerando o aluno, o contexto, os recursos, seleção de metodologias e estratégias; iii) competências pessoais relacionadas com o desenvolvimento intra e interpessoal do professor (saber ser, saber relacionar, saber comunicar e partilhar num prisma de desenvolvimento pessoal).

A autora também indicou oficinas, projetos e círculos de estudos como modalidades de preparação de professores, tendo em vista que possibilitam mobilização, iniciativa, o saber oriundo das experiências, bem como contextualização do trabalho. Essa é uma 
maneira de superar uma concepção de formação de professores concentrada apenas em repasse de conhecimentos, orientando a ação docente rumo ao desenvolvimento profissional e pessoal, baseado na reflexão sobre ação, análise lógica de desestruturação e reconstrução de saberes, objetivando aprimorar a prática, estudando o cotidiano da escola.

Cruz (2006) resumiu características essenciais à formação docente por muito contribuírem para qualidade no trabalho dos professores na escola da atualidade: comprometimento; domínio de conteúdo; flexibilidade ou abertura para mudanças; reflexibilidade ou capacidade de análise e juízo crítico de seu próprio fazer docente; capacidade de trabalhar em equipe. Todos esses traços importam à formação docente na perspectiva interdisciplinar e à qualidade nas práticas docentes.

Considerando a questão da "atitude" na interdisciplinaridade, Fazenda (2011) enfatizou a preparação de professores como objeto de análise e pesquisas dos principais centros de referência em estudos de interdisciplinaridade. E adiantou que a formação interdisciplinar docente "[...] deveria ser considerada de um ponto de vista circundisciplinar, em que a ciência da educação fundamentada em um conjunto de princípios, de conceitos, de métodos e de fins converge para o plano metacientífico [...]” e explicou:

\footnotetext{
Tratamos nesse caso, do que poderíamos chamar de interação envolvente, sintetizante e dinâmica, reafirmando a necessidade de uma estrutura dialética, não linear e não hierarquizada, em que o ato profissional de diferentes saberes construídos pelos professores não reduza apenas aos saberes disciplinares. [...] A circundisciplinaridade não exclui a necessidade de uma formação disciplinar, indispensável no processo de teorização das práticas, mas, como denomina Freitag, 1995, o desenvolvimento de um corpo sintético de conhecimentos debruçando-se sobre um sistema teórico, visando a uma síntese explicativa, preditiva e compreensiva. (FAZENDA, 2011, p. 156-157)
}

Nessa experiência, a pesquisadora esclareceu que a interdisciplinaridade na formação do professor solicita competências alusivas às maneiras de intervenção e às condições que contribuem para o melhor exercício da docência. Portanto, as competências desenvolvidas requerem conjugação de diferentes saberes disciplinares oriundos da experiência, da técnica e da teoria, que interajam sem hierarquia ou linearidade, considerando igualmente as possibilidades colaborativas dos diversos conhecimentos.

Segundo a autora, a formação interdisciplinar de professores envolve "[...] interação envolvente, sintetizante e dinâmica [...]" (FAZENDA, 2011, p. 156) referente ao trabalho 
em equipe, a comunicação e trocas contínuas entre os sujeitos na relação de ensino e aprendizagem. Esclareceu, ainda, que nessa intervenção educativa, mais importante que o produto é o processo.

Fazenda (2011) ponderou que se a interdisciplinaridade for definida apenas como junção de disciplinas, o currículo é pensado apenas na organização de sua grade; entretanto, se a interdisciplinaridade é interpretada como "atitude de ousadia", busca de conhecimento, é necessário pensar na cultura do lugar onde se formam professores, elucidando o espectro epistemológico e praxiológico. Nesse sentido, elucidou que entender interdisciplinaridade como interação existente entre disciplinas pode sugerir apenas a simples comunicação de ideias até a integração mútua de conceitos. Todavia tal definição é muito abrangente e insuficiente para dar fundamento a práticas interdisciplinares na formação de professores.

Diante disso, explicitou que Fourez (2001 apud FAZENDA 2011) tomou duas ordenações diferentes e complementares para compreender a formação interdisciplinar de professores. A ordenação científica, que destacou a cultura do saber/saber; e a ordenação social que enfatizou a cultura do saber/fazer. Na primeira, a construção dos saberes interdisciplinares tomou como base a essência do conhecimento científico para formar professores, com estruturação hierárquica das disciplinas, organização e dinâmica, interação dos artefatos que as constituem, mobilidade conceitual, comunicação de saberes e sequências organizadas. Nessa ordenação, cada disciplina será analisada não só na grade curricular, mas considerando os saberes que trazem e o movimento que eles criam, específico de sua área de cientificidade. Na ordenação social, procurou-se relacionar o saberes científicos disciplinares às necessidades sociais, econômicas e políticas. Nessa ordem, emergiu o problema da dissociação entre o conhecimento científico e a demanda social. A pesquisadora concluiu:

Tal concepção coloca em questão toda a separação entre a construção das ciências e a solicitação das sociedades. No limite, diríamos mais, que esta ordenação tenta captar toda complexidade que constitui o real e a necessidade de levar em conta as interações que dele são constitutivas. Estuda métodos de análise do mundo, em função das finalidades sociais, enfatiza os impasses vividos pelas disciplinas científicas em suas impossibilidades de sozinhas enfrentarem problemáticas complexas. (FAZENDA, 2011, p.151)

A autora mencionou que Lenoir (2001 apud FAZENDA 2011) apontou uma terceira ordenação: a interacional. Como a cultura do saber ser, forma tipicamente 
brasileira de formar professores. Saber ser interdisciplinar, na qual a experiência docente é considerada em três dimensões: do sentido, da intenção e da funcionalidade, distinguindo o contexto científico do profissional e do prático. A interdisciplinaridade apresentada nessa perspectiva revela que os cursos de formação inicial de professores ainda deixam muito a desejar, por não oferecerem aos estudantes experiências enlaçadas à escola, impossibilitando a construção do conhecimento contextualizado, derivado da prática, se limitando a simulações e estágios incompletos.

Nesse sentido, para Imbernón (2005) a prática deve ser o eixo central sobre o qual se apoia a formação do conhecimento profissional básico dos cursos das licenciaturas. E o currículo formativo deve oferecer conhecimento basilar, promovendo experiências interdisciplinares para permitir que o licenciando consiga integrar conhecimento e procedimentos das várias disciplinas ou disciplina com visão psicopedagógica, com a qual possa integralizar e relacionar o conhecimento didático do conteúdo com o psicopedagógico, contextualizando e tornando significativos os saberes laborados, contemplando as muitas dimensões da realidade do indivíduo.

Para isso, sugeriu que a formação inicial precisa superar o modelo de transferência de conhecimentos formais e formas culturais preestabelecidas, estáticas e fixas, e propiciar aos estudantes o desenvolvimento da atitude investigativa, aliando teoria e prática, bem como incentivar a observação, o debate, a reflexão, a análise da realidade social, o estudo de casos e aproximação da escola. A dissociação entre o conhecimento e o cotidiano tem formado profissionais imaturos e pouco criativos quando defrontados pelos problemas que o dinâmico mundo do trabalho apresenta.

Diante dessas assertivas, pensamos acerca do papel do professor na atualidade. No mundo em que as informações estão facilmente acessíveis, percebemos mudança no trabalho docente, impelida pela situação na qual compete ao professor mediar a relação do aluno com o conhecimento disponível nas mídias. Esse trabalho exige contextualização que possibilite o desenvolvimento de habilidades para aprender, analisar criticamente a realidade, atuar de forma criativa e transformadora, aptidão para enfrentar o emaranhado dos problemas sociais da época e posicionar-se construtivamente.

Nesse sentido, Pimenta (2012, p. 25) afirmou que a educação escolar deve basearse no trabalho do professor e alunos com o objetivo de elaborar a humanização e desenvolvimento de ambos pelo trabalho coletivo e interdisciplinar. Considerando a função social da escola e a complexidade da sociedade globalizada, a formação de professores 
solicita a construção de conhecimentos científico, técnico e social, numa perspectiva interdisciplinar.

Analisando os saberes da docência, a autora mencionou a fragmentação dos conhecimentos nos cursos de licenciaturas e a necessidade de instituir a prática como ponto central desses cursos, "reinventando os saberes pedagógicos a partir da prática social da educação". Para isso, sugeriu um balanço crítico da formação inicial e continuada de professores para que contemplem: novas lógicas de organização curricular, interdisciplinaridade, currículos articulados a escolas-campo de trabalho dos professores e ao estágio, superando a fragmentação tradicional da formação docente em saberes da experiência, científicos e pedagógicos. A autora escreveu:

\footnotetext{
Considerar a prática social como o ponto de partida e como ponto de chegada possibilitará uma ressignificação dos saberes na formação de professores. As consequências para a formação dos professores são que a formação inicial só pode se dar a partir da aquisição da experiência dos formados (ou seja, tomar a prática existente como referência para a formação) e refletir nela. $\mathrm{O}$ futuro profissional não pode constituir seu saber-fazer senão a partir de seu próprio fazer. (PIMENTA, 2012, p. 25-26)
}

Outro aspecto importante que a aprendizagem baseada em situações práticas propicia é a problematização com abertura para o desenvolvimento do espírito de pesquisa que caracteriza a prática interdisciplinar. Fazenda (2013, p. 21) declarou: “[...] o docente interdisciplinar aprende a ser pesquisador da própria prática $[. .$.$] ". No fazer docente, a$ experiência é um espaço de investigação e reflexão, campo fértil para construção e reconstrução do conhecimento.

Quando iniciamos o ensaio, destacamos a necessidade da formação de professores vinculada à escola, em que a teoria se enlaça à prática e gera conhecimentos novos e significativos, propiciando espaço para a pesquisa. Para formar-se professor, submete-se a um processo contínuo, que se estenderá por toda vida, face à singularidade da profissão docente e seu caráter social, imediatamente relacionado ao desenvolvimento histórico e cultural. Nesse aspecto, concordamos com Leite et al (2013, p.43):“[...] a pesquisa constitui um instrumento epistemológico e metodológico do processo de construção do conhecimento do professor em formação inicial ou continuada e eixo que articula teoria e prática docente como fonte de pesquisa." 
Nessa lógica, Alvarado Prada, Freitas e Freitas (2010, p. 370) focalizaram a FCPS Formação Continuada de Professores em Serviço. Sustentaram que a formação de professores deve ser realmente contínua e realizar-se numa proposta de pesquisa coletiva no próprio espaço da escola, de forma contextualizada, partindo de problemas surgidos da realidade cotidiana e professores atuando como pesquisadores. Defenderam que os professores desenvolvem-se precipuamente nos contextos de trabalho, na escola, “[...] onde criam relações alicerçadas em estruturas complexas que as sustentam ou permitem suas alterações [...]" e, por isso, a formação continuada, enquanto campo de pesquisa, contribui para que o docente se desenvolva profissionalmente para atuar nessa realidade específica.

Esses pesquisadores afirmaram, também, que os cursos de formação continuada não terão sucesso se não considerarem: as características do professor; suas necessidades e expectativas pessoais e profissionais, seus contextos de trabalho e a cultura de sua escola. Por isso, evidenciaram a formação continuada em serviço, pois a escola também é um espaço de formação. Diante disso, propuseram a pesquisa coletiva, na qual se pode associar pesquisa à formação do docente, vez que professores de uma escola podem se unir para desenvolver um projeto de formação continuada em seu próprio ambiente de trabalho, construindo seu próprio objeto de pesquisa-formação, com os problemas de seu contexto, que podem permitir a compreensão e transformação da sua realidade.

A articulação entre pesquisa, formação docente, trabalho em equipe e interdisciplinaridade possibilita a educação integral do licenciando, propiciando o desenvolvimento do pensamento crítico, criativo e transformador da realidade educacional. Somente assim haverá superação dos cursos de formação tecnicista, próprios da ideologia capitalista, que visam somente à repetição das teorias, sem prática, limitando a ação docente à formação de indivíduos para o mercado de trabalho. Lembramos Imbernón (2005, p. 60) quando afirmou que a formação inicial precisa superar o modelo profissional docente "[...] técnico-continuísta, que reflete um tipo de educação que serve para adaptar criticamente os indivíduos à ordem social e torna o professor vulnerável ao entorno econômico, político e social [...]”.

\section{Considerações finais}

Formação de professores não é tema para conclusões definitivas, considerando o inacabamento da ação educativa e o papel social do professor ao abrir portas para o mundo 
e apresentar a realidade cotidiana ao aprendiz, que precisará de habilidades para leitura de uma sociedade em sucessivas transformações e complexos desafios.

Investigamos a bibliografia geral e a legislação-base da educação e identificamos concepções, características, fundamentos epistemológicos, obstáculos e possibilidades da interdisciplinaridade. Também pudemos observar estudos e pesquisas publicadas que discutem pontos essenciais da formação dos professores e a perspectiva interdisciplinar.

Concluímos que a preparação de professores requer não somente conhecimento específico de uma disciplina, mas também a prática do fazer docente no aspecto pedagógico desenvolvido no contexto da escola, mediante reflexões problematizadas e atitudes investigativas. Nesse sentido, estudos dos pesquisadores convergem para a prática interdisciplinar na escola. Existem também direcionamentos claros nos documentos; entretanto, as instituições de educação superior ainda caminham lentamente no sentido de estabelecer um espaço para a prática da interdisciplinaridade nos cursos de formação inicial de professores, por falta de políticas públicas que propiciem condições e recursos para realização das intenções expressas na legislação.

É certo que a formação inicial dos professores alberga momento muito oportuno para a experiência da cultura interdisciplinar, pois, essa aprendizagem refletirá na sala de aula da Educação Básica e da Educação Superior. Para isso, a universidade precisa fazer parceria com as escolas e criar um ambiente de interação entre teoria e prática, no qual o futuro professor possa formar-se vivenciando a interdisciplinaridade, habilitando-se para o trabalho em equipe, para a pesquisa nascida da inquietação, da problematização que emana da sala de aula e da realidade desafiadora.

Diante dos apontamentos coletados, certificamos que a parceria entre universidade e escola-campo, o trabalho em equipe e a criação de um ambiente de pesquisa na formação inicial e continuada do professor consolidam a base fértil para a prática da interdisciplinaridade, por sintetizarem os elementos que a constituem.

\section{Referências}

ALVARADO PRADA, Luís Eduardo; FREITAS, Thaís Campos; FREITAS, Cinara Aline. Formação continuada de professores: alguns conceitos, interesses, necessidades e propostas. Revista Diálogo Educacional, Curitiba, v.10, n. 30, p. 367-387, maio/ago. 2010 . 
BRASIL. Constituição (1988). Constituição República Federativa do Brasil: texto consolidado até a Emenda Constitucional n. 88, de 07 de maio de 2015. Brasília: Planalto, $2015 . \quad$ Disponível em: $<$ http://www.planalto.gov.br/ccivil_03/constituicao/constituicao.htm>. Acesso em: 20 nov. 2015.

. Ministério da Educação. Lei n. 9.394, de 20 de dezembro de 1996. Dispõe sobre as diretrizes e bases para a educação nacional. Ministério da Educação. Disponível em: < http://portal.mec.gov.br/arquivos/pdf/ldb.pdf>. Acesso em: 20 nov. 2015.

. Resolução n. 1, em 18 de fevereiro de 2002. Institui as Diretrizes Curriculares Nacionais para a Formação de Professores da Educação Básica, em nível superior, curso de licenciatura, de graduação plena. Conselho Nacional de Educação. Ministério da Educação. Disponível em: <http://portal.mec.gov.br/seesp/arquivos/pdf/res1_2.pdf $>$. Acesso em: 20 nov. 2015.

COSTA E SILVA, Ana Maria. A formação contínua de professores: uma reflexão sobre as práticas e as práticas de reflexão em formação. Educação \& Sociedade. Portugal: ano XXI, n.72, agosto de 2000 .

FAZENDA, Ivani Catarina Arantes. Interdisciplinaridade: qual o sentido? São Paulo: Paulus, 2003.

. Integração e Interdisciplinaridade no Ensino Brasileiro Efetividade e

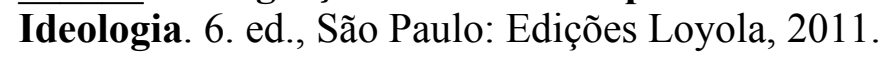

. A pesquisa como eixo da formação de docentes interdisciplinares. In: FAZENDA, Ivani Catarina Arantes; FERREIRA, Nali Rosa Silva (Orgs.). Formação de Docentes Interdisciplinares. Curitiba: CVR, 2013. p. 17-28.

FELDMAN, Marina Graziela. Formação Docente e Contexto Institucional. In: FAZENDA, Ivani Catarina Arantes (Org.). Interdisciplinaridade, pensar, pesquisar e intervir. São Paulo: Cortez, 2014. p. 117-121.

FERNÁNDEZ CRUZ, Manuel. Conceptualizacióndeldesarrollo Professional docente. In: Desarrollo Professional docente. España: Grupo Editorial Universitário, 2006, p. 9-30. FREIRE, Paulo. Pedagogia da Autonomia: Saberes necessários à prática educativa. São Paulo: Paz e Terra, 1996.

GARCÍA, Carlos Marcelo. Formação Inicial de Professores. In Desenvolvimento profissional e profissionalização dos professores. Formação de Professores para uma mudança educativa. Lisboa: Porto Editora, 1999, p. 72-103.

GATTI, Bernadetti A.; SÁ BARRETO, Elba Siqueira de. Professores do Brasil: impasses e desafios. Brasília: Unesco. 2009.

GUSDORF, Georges. Prefácio. In: JAPIASSU, Hilton. Interdisciplinaridade e patologia do saber. Rio de Janeiro: Imago, 1976. 
IMBERNÓN, Francisco. Formação Docente e Profissional: formar-se para a mudança e a incerteza. 5. ed. São Paulo: Cortez, 2005.

JAPIASSU, Hilton. Interdisciplinaridade e patologia do saber. Rio de Janeiro: Imago, 1976.

LEITE, Alexandre César Cunha et al. Interdisciplinaridade, práticas curriculares e a formação do docente interdisciplinar. In: FAZENDA, Ivani Catarina Arantes; FERREIRA, Nali Rosa Silva (Org.). Formação de Docentes Interdisciplinares. Curitiba: CVR, 2013. p. 35-53.

MATTOS, Manuel Santos. Teorias e Práticas de Formação. Contributos para a Reabilitação do Trabalho Pedagógico. Porto. ASA, 1999.

MASETTO, Marcos. Didática: a aula como centro. São Paulo: FTD, 1997.

MORIN, Edgar. Os sete saberes necessários a educação do futuro. Tradução de Catarina Eleonora de F. da Silva e Jeanne Sawaya. 8. ed. São Paulo: Cortez; Brasília, DF: UNESCO, 2003.

A cabeça bem feita. 13. ed. Rio de Janeiro: Bertrand Brasil, 2007.

Introdução ao Pensamento Complexo. 4. ed. Porto Alegre: Sulina, 2011.

NEVES, Carmem Moura de Castro. Formação de professores da educação básica e pósgraduação: a interdisciplinaridade necessária. In: PHILIPPI JÚNIOR, Arlindo; FERNANDES, Valdir (Ed.). Práticas Interdisciplinares no Ensino e Pesquisa. Barueri, São Paulo: Manole, 2015. p. 471-499.

PIAGET, Jean. Para onde vai a educação? 18. ed. Rio de Janeiro:José Olympio, 2007.

PIMENTA, Selma Garrido. Formação de professores: identidade e saberes da docência. _. (Org.). Saberes Pedagógicos e atividades docentes. 8. ed. São Paulo: Cortez, 2012.

SAVIANI, Dermeval. Formação de Professores: aspectos históricos e teóricos do problema no contexto brasileiro. Revista Brasileira de Educação v. 14, n. 40, jan./abr. 2009.

SHULMAN, Lee S. Conocimiento y enseñanza: fundamentos de lanueva reforma. Professorado. Revista de Currículum y formación Del professorado, vol. 9, n.2, p. 1-30, 2005. Disponível em: http://www.ugr.es/ recfpro/Rev92.html. Acesso em: 10/11/2011.

UNESCO. Educação: um tesouro a descobrir; relatório para a UNESCO da Comissão Internacional sobre Educação para o Século XXI. 2. ed. São Paulo: Cortez; Brasília, DF, 2003.

RECEBIDO EM: 12/12/2015

APROVADO EM: 23/02/2016 